\title{
Directions in Research: Language and the Body
}

\author{
Barbara Fox \\ Linguistics Department \\ University of Colorado, Boulder
}

I am a linguist, most strongly identified with the discourse-functional approach to syntax (or grammar-I'll use those terms interchangeably). Although this community of scholars is not always concerned with social interaction, various members have noted the need to include social-interactional functions of language among the functions of syntax that we examine (e.g., Ford, 1993; Ford \& Fox, 1996).

The research questions that I am currently most excited by focus on language as an embodied practice. ${ }^{1}$ Such questions seek to understand the interrelations among more traditional areas of linguistics like grammar and semantics (although perhaps differently understood) and conversational organization on the one hand, and gesture and prosody on the other. The significance of these interrelations for everyday conversational language has been explored by a variety of scholars from different disciplines, and it is this trend in research that I am finding most compelling (e.g., Ford, Fox, \& Thompson, 1996a, 1996b; Ford \& Thompson, 1996; Fox, 1995; C. Goodwin, 1979, 1981; C. Goodwin \& Goodwin, 1987; M. H. Goodwin, 1995; Jasperson, 1998; McNeill, 1992; Schegloff, 1996).

The suggestion that language - and all human behavior-is embodied is not new. It can be found in the works of Merleau-Ponty (see Sallis, 
1981), and, at least under some interpretations, of Heidegger (see Heidegger, 1962; Dreyfus, 1991). Dreyfus (1972/1993) argued over 20 years ago that artificial intelligence would fail as an enterprise if it did not take into account the fact that humans have bodies that live in and through socially constructed spaces.

Nonetheless, although the general claim is not new, there has been relatively little systematic study of the obviously bodied practices, such as gesture, body movements, ${ }^{2}$ and prosody, and their relations to the less obviously bodied practices, such as grammar, semantics, and sequential organization, in everyday conversation.

My particular interest in everyday conversation has most recently focused on turn-taking, and in this domain it has long been clear that recipients attend to prosodic and gestural features of the talk, as well as to grammar, in determining when a speaker might be done with his or her turn (e.g., Duncan, 1974; Duncan \& Fiske, 1977; Sacks, Schegloff, \& Jefferson, 1974; more recently, Berkovits, 1984; Ford, Fox, \& Thompson, 1996a; Ford \& Thompson, 1996; C. Goodwin, 1979, 1981; Lehiste, 1979; Local, Kelly, \& Wells, 1986; Local, Wells, \& Sebba, 1985; Schaffer, 1983; Wells \& Peppe, 1996). It is thus very clear from this work that all of these practices interact in everyday conversation.

Nonetheless, even in this domain very little systematic work has been done on the interactions of prosody, gesture, grammar, semantics, and sequential location, especially in the area of turn projection. By turn projection I mean the display by speakers through the construction of their utterance how and when that utterance might come to completion in the (very near) future. For example, I know of only one study on how prosody might project upcoming turn completion before the final two syllables (Grosjean, 1983). ${ }^{3}$ Additionally, there are not many studies of the gestural practices employed in turn projection (e.g., C. Goodwin, 1979, 1981; Schegloff, 1984; Streeck, 1993). Thus, the complex relations among prosody, grammar, semantics, sequential organization, and gesture in projecting turn completion have been noted but have not yet been systematically explored. From my perspective, then, this fruitful area deserves further study.

Prosody, gesture, grammar, semantics, and sequential location of course interact in other facets of everyday conversation as well. C. Goodwin and Goodwin (1987), for example, described the prosodic, lexical, and syntactic properties of assessments. Couper-Kuhlen and Selting (1996) also explored these interfaces in their contributions. It is almost certainly the

\section{Copyright $(2000$ All Rights Reserved}


case that prosody and gesture interact with semantics, grammar, and sequential location in many - and perhaps every - question of grammatical usage. For the purposes of this article, I will focus on the domain of turn-taking, but it should be kept in mind that turn-taking is just one window through which one can observe the embodiment of language.

In the remainder of this article I further motivate my interest in embodied language by exploring the role of prosody and gesture in turn-taking. I first attempt to motivate my interest-as someone committed to a discourse-functional approach to syntax-in turn-taking, and then motivate my interest in prosody and gesture. Because of space limitations, these comments will be brief.

\section{GRAMMAR, GESTURE, AND PROSODY IN TURN PROJECTION}

\section{Why Turn-Taking?}

As Sacks, Schegloff, and Jefferson (1974) pointed out, turn-taking is a pervasive organizational property of human interaction. All social systems that allow access to multiple individuals must provide for some form of turn-taking. The significance of turn-taking as a principle of human interaction is thus vast; given that turn-taking in conversation is managed almost entirely through language, we can see that one major function of language is to accomplish this crucial social function. Therefore, anyone interested in the functions of language could potentially find turn-taking to be an important function of language.

Moreover, as with other functions of language, it is not just that a particular language is deployed to fulfill the needs of turn-taking; rather, that language is almost certainly shaped by turn-taking needs (e.g., Fox, Hayashi, \& Jasperson, 1996; Schegloff, 1996). Schegloff (1996) argued this point quite persuasively for syntax. Thus, even someone who considers their domain of research to be syntax-in-discourse might find that answers to certain crucial syntactic questions lie in the nature of conversational turn-taking.

Also, to extend the logic: If we find that the syntax of a language both shapes and is shaped by turn-taking, and if we find that turn-taking

\section{Copyright $(2000$ All Rights Reserved}


is constituted in part by prosodic and gestural practices, then we might be led to explore the ways in which syntax, prosody, and gesture work together and how they might, in fact, be constitutive of each other. It is this possibility that I am currently interested in pursuing.

\section{Why Prosody and Gesture}

In the early work on turn-taking in conversation, special emphasis was placed on the role of grammar in turn projection - that is, in indicating how and when the current turn might come to possible completion (Sacks, Schegloff, \& Jefferson, 1974). Even in that early work, however, the importance of intonation was acknowledged.

More recent work on turn projection has demonstrated that grammatical projection is always accompanied by gesture, intonation, and other aspects of vocal production, and is done in particular sequential locations, which creates a locus of interpretation and thereby shapes projection (e.g., Ford, Fox, \& Thompson, 1996a, 1996b; Ford \& Thompson, 1996; Fox, 1995). Consider an example to see what is meant by such a statement.

The following fragment comes from a videotape, made in the early 1970s, of three couples (and various children and dogs) enjoying a backyard picnic in Central Ohio. ${ }^{4}$ The fragment (and the videotape) starts with Pam encouraging Curt to tell a joke that he had already told. The discussion is based on Fox (1995).

Pam:
$\begin{aligned} & \text { Uh-cuz they } \\ & \text { Carney: }\end{aligned}$
Curt:
Gary:




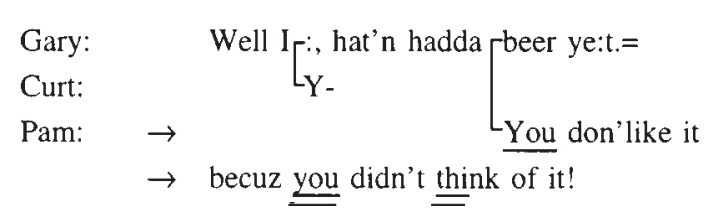

In this interaction, Pam has suggested that someone tell a joke, perhaps for the benefit of the camera, which the others have already heard. Several people respond to Pam's suggestion, including Gary, who says "I don't think it's that funny." Different participants then orient to Gary's reaction: It is Pam's response to Gary, "You don' like it becuz you didn't think of it!", that I want to explore further.

If we temporarily ignore context, there are a variety of places at which Pam's word string could hypothetically be complete:

You.

You don'.

You don'like it.

You don'like it becuz you didn't.

You don'like it becuz you didn't think.

You don'like it becuz you didn't think of it.

Yet given the sequential location-Pam is responding to Gary's "I don't think it's that funny," and after Carney and Curt have also responded-only a few of these are possibly relevant contributions, and each of these would have to be said with a particular prosody to be recognizable as doing that utterance, and hence as upcomingly complete. For example, for "You" to be a hearably complete utterance in this sequential location, it would probably have to show a complete pitch contour, either terminal rising or falling.

Pam's actual utterance begins with "You," which is strongly accented. The pitch comes down on "don" "and there is no accent on "like," indicating that after the direct object may not be a place of possible completion. Furthermore, "it" is produced at the same pitch as "like," so there is no suggestion of completion-relevant fall or rise. From these properties we do not hear the end of "it" as a likely place of completion (even though it is syntactically complete as a clause). Having thus heard "You don'like it," the recipients may anticipate that more of this turn will come-and in fact the speaker does continue with a subordinate clause. In this "because" clause the accent on "think" indicates a possible

\section{Copyright $(2000$ All Rights Reserved}


upcoming completion after the object, which in fact occurs. Therefore, it is not the syntax or sequential location alone that helps the recipients to know when the turn might be complete-the pitch movement (and other facets of the prosody) plays a crucial role as well. Prosody-which is really the vocal production of suprasegmentals - is an obviously bodied set of practices.

Because Pam is off-camera when she produces this utterance, it is not possible for us to explore the role of gesture in the projection of her turn. To see the importance of gesture-another obviously bodied set of practices - in turn projection, consider another example.

The following fragment comes from a videotape of a dinner-table conversation between two couples (and the host couple's two children). The guests, Don and Ann, have been telling about the new house of a friend of theirs that they have just visited. The discussion focuses on Beth's response:

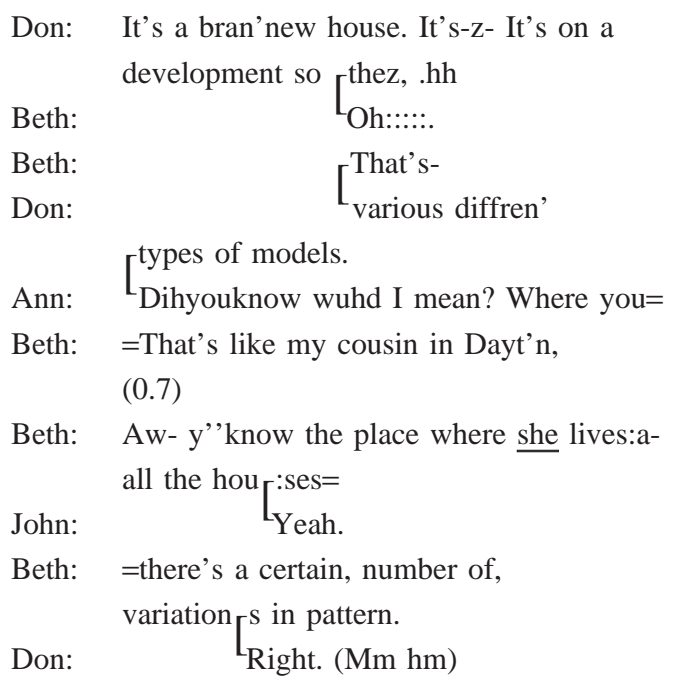

As Beth begins this turn (with "That's like my cousin in Dayt'n,"), she is holding a fork in her right hand and her left hand is in her lap. After a lack of uptake to this beginning, she continues by elaborating on the similarity between the development where her cousin lives and the development just described by Don. As she enters this elaboration, she brings her left hand from her lap to above her plate, and as the utterance progresses she sketches out with her left hand several clockwise oval-like shapes, done 
jerkily (as if describing "stops" along the route). Partway through the word "variations," her left hand begins a return to her lap. This return, or retraction as it is known in the gesture literature (e.g., Kendon, 1972; McNeill, 1992), may display that the turn is coming to a place of possible completion; in fact, not long after this retraction begins, Don responds to Beth's utterance—-before it is actually complete—with "Right." Therefore, it is very possible that Don is attending to the trajectory of Beth's gesture as a display of when the turn will come to completion.

The movement of the hand in this complex utterance thus illustrates one way in which gesture can accomplish turn projection-recipients can inspect a gestural movement for where it might return to a resting place and find that place, if it coincides with other indications of completion (through grammar, prosody, and sequential location), as a possible end of the turn.

In summary, then, we can see that prosody, gesture, grammar, semantics, and sequential location work together to project possible turn completion. In fact, it is probably more accurate to say that they mutually create or constitute one another, which opens up the very intriguing possibility that grammar itself may be an embodied practice (see Fox, 1995, for a fuller exploration of this possibility).

\section{DISCUSSION}

I hope in this short statement to have motivated an interest in embodied language, in particular in the interrelations among prosody, gesture, syntax, and sequential location in everyday conversation.

\section{NOTES}

1 Here the phrase should actually be "embodied and socially constituted practice," because it is only through social practices of interpretation that actions of the body acquire significance.

2 In what follows I will use the term gesture to include all movements of the externally visible body, including gaze.

3 Schegloff (1988) discussed a possible relation between pitch peak and turn completion but did not provide evidence for this relation.

\section{Copyright (C) 2000 All Rights Reserved}


4 I am grateful to Candy and Chuck Goodwin for allowing the use of the tapes and the accompanying transcripts I have used for this article.

\section{REFERENCES}

Berkovits, R. (1984). Duration and fundamental frequency in sentence-final intonation. Journal of Phonetics, 137, 255-265.

Couper-Kuhlen, E., \& Selting, M. (Eds.). (1996). Prosody in conversation. Cambridge, England: Cambridge University Press.

Dreyfus, H. (1993). What computers still can't do. Cambridge, MA: MIT Press. (Original work published 1972)

Dreyfus, H. (1991). Being-in-the-world. Cambridge, MA: MIT Press.

Duncan, S. (1974). Some signals and rules for taking speaker turns in conversations. In S. Weitz (Ed.), Nonverbal communication (pp. 298-311). New York: Oxford University Press.

Duncan, S., \& Fiske, D. W. (1977). Face to face interaction. Hillsdale, NJ: Lawrence Erlbaum Associates, Inc.

Ford, C. (1993). Grammar in interaction: Adverbial clauses in American English conversations. Cambridge, England: Cambridge University Press.

Ford, C., \& Fox, B. (1996). Interactional motivations for reference formulation: He had.This guy had a beautiful, thirty-two O:lds. In B. Fox (Ed.), Studies in anaphora (pp. 145-168). Amsterdam: John Benjamins.

Ford, C., Fox, B., \& Thompson, S. (1996a). Practices in the construction of turns: The 'TCU' revisited. Pragmatics, 6, 427-454.

Ford, C., Fox, B., \& Thompson, S. (1996b, November). Simultaneous practices of turn projection. Paper presented at the meeting of the American Anthropological Association.

Ford, C., \& Thompson, S. (1996). Interactional units in conversation: Syntactic, intonational, and pragmatic resources for the projection of turn completion. In E. Ochs, E. Schegloff, \& S. Thompson (Eds.), Grammar and interaction (pp. 134-184). Cambridge, England: Cambridge University Press.

Fox, B. (1995, July). On the embodied nature of grammar: Embodied being-in-the-world. Paper presented at the International Conference on Functional Approaches to Grammar, University of New Mexico, Albuquerque.

Fox, B., Hayashi, M., \& Jasperson, R. (1996). Resources and repair: A cross-linguistic study of syntax and repair. In E. Ochs, E. Schegloff, \& S. Thompson (Eds.), Grammar and interaction (pp. 185-237). Cambridge, England: Cambridge University Press.

Goodwin, C. (1979). The interactive construction of a sentence in natural conversation. In G. Psathas (Ed.), Everyday language: Studies in ethnomethodology (pp. 97-121). New York: Irvington.

\section{Copyright (C) 2000 All Rights Reserved}


Goodwin, C. (1981). Conversational organization: Interaction between speakers and hearers. New York: Academic.

Goodwin, C., \& Goodwin, M. H. (1987). Concurrent operations on talk: Notes on the interactive organization of assessments. Papers in Pragmatics, 1, 1-54.

Goodwin, M. H. (1995, July). Games of stance: Conflict and footing in hopscotch. Paper presented at the Symposium on Conversation, Albuquerque, NM.

Grosjean, F. (1983). How long is the sentence? Prediction and prosody in the on-line processing of language. Linguistics, 21, 501-529.

Heidegger, M. (1962). Being and time. San Francisco: HarperCollins.

Jasperson, R. (1998). Repair after cut-off. Unpublished doctoral dissertation, University of Colorado, Boulder.

Kendon, A. (1972). Some relationships between body motion and speech. In A. Siegman \& B. Pope (Eds.), Studies in dyadic communication (pp. 177-210). Elmsford, NY: Pergamon.

Lehiste, I. (1979). Perception of sentence and paragraph boundaries. In B. Lindblom \& S. Ohman (Eds.), Frontiers of speech communication research (pp. 191-201). New York: Academic.

Local, J., Kelly, J., \& Wells, W. H. G. (1986). Towards a phonology of conversation: Turn-taking in Tyneside English. Linguistics, 22, 411-437.

Local, J., Wells, W. H. G., \& Sebba, M. (1985). Phonology for conversation: Phonetic aspects of turn delimitation in London Jamaican. Journal of Pragmatics, 9, 309-330.

McNeill, D. (1992). Hand and mind. Chicago: University of Chicago Press.

Sacks, H., Schegloff, E., \& Jefferson, G. (1974). A simplest systematics for the organization of turn-taking for conversation. Language, 50, 696-735.

Sallis, J. (Ed.). (1981). Merleau-Ponty, perception, structure, language. Atlantic Highlands, NJ: Humanities.

Schaffer, D. (1983). The role of intonation as a cue to topic management in conversation. Journal of Phonetics, 136, 243-257.

Schegloff, E. (1984). On some gestures' relation to talk. In M. Atkinson \& J. Heritage (Eds.), Structures of social action (pp. 266-296). Cambridge, England: Cambridge University Press.

Schegloff, E. (1988). Discourse as an interactional achievement II. In D. Tannen (Ed.), Linguistics in context: Connecting observation and understanding (pp. 135-158). Norwood, NJ: Ablex.

Schegloff, E. (1996). Turn organization: One intersection of grammar and interaction. In E. Ochs, E. Schegloff, \& S. Thompson (Eds.), Grammar and interaction (pp. 52-133). Cambridge, England: Cambridge University Press.

Streeck, J. (1993). Gesture as communication I. Communication Monographs, 60, 275-299.

Wells, B., \& Peppe, S. (1996). Ending up in Ulster: Prosody and turn-taking in English dialects. In E. Couper-Kuhlen \& M. Selting (Eds.), Prosody in conversation (pp. 101-130). Cambridge, England: Cambridge University Press.

\section{Copyright @ 2000 All Rights Reserved}

